\title{
A Descriptive Study on Perceived Levels of Stress, Coping and Their Correlation in Retirees of Kashmir Valley
}

Shabir Ahmad Dar ${ }^{1 *}$, Ifshana Iliyas ${ }^{1}$, Tabasum Dilawar ${ }^{1}$ and Temheeda Rahman ${ }^{2}$

${ }^{1}$ Department of Psychiatry, Government Medical College Srinagar, Srinagar, Jammu and Kashmir, India

${ }^{2}$ Sheri Kashmir Institute of Medical Sciences, Soura, Srinagar, Jammu and Kashmir, India

\begin{abstract}
Background: Retirement is a major and fundamental life change that affects numerous areas. The transition from a life of work to one of retirement has both practical and emotional implications. Apart from physical health issues, they are more likely to suffer from mental and psychological distress.
\end{abstract}

Materials and methods: A descriptive, cross-sectional study was conducted among 100 retirees of district Srinagar from June 2015 to June 2016, using a semi-structured questionnaire. Levels of Stress and coping among retirees were assessed using the Depression Anxiety Stress Scales and Brief COPE scale.

Results: Nearly $40(40 \%)$ of cases had moderate level (10-12), 03(03\%) had severe level (13-16), 04(04\%) had extremely severe level $(17+)$, and around $35(35 \%)$ had no stress (0-7). Majority of retired employees $85(85 \%)$ either used average level (57-84), or used good level (85-112) of coping with a minority $10(10 \%)$ using low level (28-56) of coping. There was a significant positive correlation between the stress and coping scores among retired employees.

Conclusion: The perceived level of stress was moderate among retired employees and the retirees used average level of coping to deal with the retirement stress. There is a need for organized family and social support to improve the physical and psychological health of retirees.

\section{Keywords: Elderly; Retirees; Stress; Coping; Correlation}

\section{Introduction}

Aging is a natural process. Old age should be regarded as a normal inevitable biological phenomenon [1]. Old age is considered by many to begin at retirement. Retirement as defined by Atchley (1977) is the act of retiring or the state of being retired. That is to withdraw oneself from business, public life or and to remove from active service. Thus, the process of retirement involves the transition of people's experience, when they move from a job role performed for pay to the role of retired person [2].

The retirement age period for central government employees are 60 years and in Jammu and Kashmir the retirement age period for employees has also been raised from 58 to 60 years on June 03, 2014 [3]. So, this age we will called as "old age". Elderly or old age consists of ages nearing or surpassing the average life span of human beings. The boundary of old age cannot be defined exactly because it does not have the same meaning in all societies. Government of India adopted 'National Policy on Older Persons' in January, 1999. The policy defines 'senior citizen' or 'elderly' as a person who is of age 60 years or above [4].

Stress is the wear and tear on the body caused by constant adjustment to an individual's changing environment. Anything that causes change in our life causes stress [5]. As people become aged, the ability to achieve a relaxation response after a stressful event becomes more difficult. Aging may simply wear out the systems in the brain that respond to stress $[6,7]$. Retirement is a major and fundamental life change that affects numerous areas. The transition from a life of work to one of retirement has both practical and emotional implications (e.g. coping with lower income, having numerous leisure hours, having to leave a familiar, well-known world), and the responses to it are individual and unique. The professional literature describes a wide range of responses to this fundamental change as well as differences in intensity and style of response among individuals involved in the retirement process [8].

Aging is the problem with almost every family involving strains and stresses in taking care of them. It has become an important socio psychological problem in the community gradually number of negligence also increased mainly diseased, disabled, and psycho physiologically deteriorated old age people [9]. Ageing is coming up as one of the biggest challenge the world over. At any age, stress is a part of life, young and old alike have face difficult situations and overcome obstacles, with increasing age, people are more susceptible to physical, psychological, social and emotional problems [10].

Retirement is a major and fundamental life change that affects numerous areas. The transition from a life of work to one of retirement has both practical and emotional implications (e.g. coping with lower income, having numerous leisure hours, having to leave a familiar, well-known world), and the responses to it are individual and unique. The professional literature describes a wide range of responses to this fundamental change as well as differences in intensity and style of response among individuals involved in the retirement process [8].

Stress and stress related problems have various effects on old age, their care giver and also in society. It may cause physical, mental, emotional and behavioral problems. Recently the studies suggest that the inability to adopt stress is associated with the onset of depression or anxiety [11]. Studies also show that depression related to stress has been recognized as the second most prevalent psychiatry condition on

*Corresponding author: Shabir Ahmad Dar, Department of Psychiatry, Government Medical College Srinagar, Srinagar, Jammu and Kashmir, India, Tel: +91-9086999830; E-mail: shabir1055@gmail.com.

Received: January 30, 2018; Accepted: March 22, 2018; Published: April 02, 2018

Citation: Dar SA, Iliyas I, Dilawar T, Rahman T (2018) A Descriptive Study on Perceived Levels of Stress, Coping and Their Correlation in Retirees of Kashmir Valley. J Psychiatry 21: 443. doi:10.4172/2378-5756.1000443

Copyright: @ 2018 Dar SA, et al. This is an open-access article distributed under the terms of the Creative Commons Attribution License, which permits unrestricted use, distribution, and reproduction in any medium, provided the original author and source are credited 
elderly population [12].

Further during the literature review the investigator have gone through a number of studies related to assessment of psycho-social problems in retired, but could not find out any studies related to assessment of stress level and coping among retirees in Jammu and Kashmir.

Keeping the above facts in view, the investigator felt it is necessary to assess the level of stress and coping among retired employees so that the knowledge obtained would be useful in formulation of recommendations to promote health of elderly and prevent the mental health issues in retires at its initial stages. All these stresses can be modified in a positive way by the use of appropriate coping strategies and stress management skills.

\section{Materials and Methods}

The present study was carried out at Mader-E-Meharban Institute of Nursing Sciences and Research SKIMS Soura from June 2015 to June 2016 in selected areas of Hazratbal Constituency in District Srinagar, Kashmir. It was an observational open label descriptive study. This research was initiated following approval by institutional ethical committee and board of research studies of Sheri Kashmir institute of medical sciences Soura, Srinagar.

The selected areas include Burzahama, Chatterhama, Tailbal, Mulfaq, Habak, Zakura, Batapora and Gassu. The selection of this area was done based on the geographical proximity, feasibility of the study and availability of respondents. In the present study, target population comprises of the retired employees above the age of 60 years. The accessible population included retired employees in Hazratbal constituency of District Srinagar.

By using Snow-ball sampling technique a total of 100 retired employees were taken after taking proper permission from block medical officer of Hazratbal constituency and Phak Citizens Welfare Forum. Written informed consent was taken from each person in locally understandable language and was assured of the confidentiality of their identity.

All the cases were interviewed for socio demographic variables like Gender, Educational qualification, family type, monthly income and years of experience. DASS-21 self-report questionnaires and Brief COPE Scale was the tool used for assessing stress and coping in retirees.

The Depression Anxiety Stress Scales (DASS-21) is a short form of DASS which is a self-report 4-point Likert scale and composed of three subscales: Depression (DASS-D), Anxiety (DASS-A), and Stress (DASS-S). The alpha reliability coefficients for the DASS-21 subscales have been examined in clinical and nonclinical samples and reported as 0.94 for DASS-D, 0.87 for DASS-A, and 0.91 for DASS-S $[13,14]$.

The Brief COPE is a 28 -item measure of situational and dispositional coping styles. Carver published the Brief COPE, a shortened version of the COPE designed for use when participant response burden is a considering factor [15].

\section{Statistical analysis}

Data was organized in Microsoft Excel sheet and was analyzed using SPSS version 20.0 and SYSTAT-13. Frequency and percentage distribution of data was done for analysis of demographic variables. Mean, mean percentage and standard deviation of data was calculated for analysis of stress and coping. Chi-square test was used to determine the association between the level of stress and coping among the participants. Karl-Pearson's co-relational coefficient was used to determine the relation between stress and coping scores. A p-value of $<0.05$ was considered statistically significant.

\section{Results}

Table 1 represents the distribution of study subjects according to their socio-demographic variables. The data obtained are described in terms of gender, educational status, type of family, monthly income and years of experience as follows:

Table 2 indicates that maximum number of retired employees, 40(40\%) had moderate level (10-12), 03(03\%) had severe level (1316), 04(04\%) had extremely severe level (17+), 18(18\%) had mild level of stress (8-9), and 35(35\%) had no stress (0-7) when measured on standardized DASS-21 measuring scale. Mean \pm SD of the stress score was $8.89 \pm 3.698$ with a mean percentage of 42.33 .

Table 3 represents that majority of retired employees $85(85 \%)$ used average level (57-84), 10(10\%) used low level (28-56) and 05(05\%) used good level (85-112) of coping. The Mean \pm SD and mean percentage was $66.07 \pm 9.361$ and 58.99 respectively. This shows that retired employees had good level of coping.

Table 4 shows that there is significant positive correlation between the stress and coping scores among retired employees in Hazratbal Constituency of District Srinagar, Kashmir. Correlation Coefficient is found to be +0.399 with table value $0.197(\mathrm{P}<0.001)$, and $\mathrm{T}$ calculated $>$ T tabulated $(0.399>0.197)$.

\section{Discussion}

With ageing comes an increased risk of developing chronic diseases and disability. Apart from physical health issues, they are more likely to suffer from mental and psychological distress [16]. Stigmatizing attitudes and common stereotypes often prevent them from participating fully in society and cause undue stress. There are several causes of stress, unique to or more common in elderly. The most frequent stressful life circumstances that affect older adults involve health, interpersonal, financial or work-related events. Loss of a spouse or separation, deaths in the family and lack of social integration are common stressors, which may themselves cause physical and mental ill-health. Physical

\begin{tabular}{|c|c|c|}
\hline Socio-demographic characteristics & Cases & Percentage \\
\hline \multicolumn{3}{|c|}{ Gender } \\
\hline Male & 74 & $74 \%$ \\
\hline Female & 26 & $26 \%$ \\
\hline \multicolumn{3}{|c|}{ Educational status } \\
\hline Middle pass & 20 & $20 \%$ \\
\hline $10+2$ & 39 & $39 \%$ \\
\hline Graduate or above & 41 & $41 \%$ \\
\hline \multicolumn{3}{|c|}{ Family Type } \\
\hline Nuclear & 49 & $49 \%$ \\
\hline Joint & 49 & $49 \%$ \\
\hline Extended & 2 & $2 \%$ \\
\hline \multicolumn{3}{|c|}{ Monthly income } \\
\hline More than 15000 & 50 & $50 \%$ \\
\hline Less than 15000 & 50 & $50 \%$ \\
\hline \multicolumn{3}{|c|}{ Years of Experience } \\
\hline More than 30 years & 60 & $60 \%$ \\
\hline Less than 30 years & 40 & $40 \%$ \\
\hline
\end{tabular}

Table 1: Distribution of study subjects according to their socio-demographic variables. 


\begin{tabular}{|c|c|c|}
\hline Levels Of Stress & Frequency & Percentage \\
\hline Normal (0-7) & 35 & $35 \%$ \\
\hline Mild (8-9) & 18 & $18 \%$ \\
\hline Moderate (10-12) & 40 & $40 \%$ \\
\hline Severe (13-16) & 3 & $3 \%$ \\
\hline Extremely Severe (17+) & 4 & $4 \%$ \\
\hline
\end{tabular}

Table 2: Stress level in retired employee.

\begin{tabular}{|c|c|c|}
\hline Coping Levels & Percentage & Frequency \\
\hline Good (85-112) & $5 \%$ & 05 \\
\hline Average (57-84) & $85 \%$ & 85 \\
\hline Low (28-56) & $10 \%$ & 10 \\
\hline
\end{tabular}

Table 3: Shows that retired employees had good level of coping.

\begin{tabular}{|c|c|c|}
\hline \multirow{2}{*}{ Pearson's Correlation } & \multicolumn{2}{|c|}{ Knowledge } \\
\cline { 2 - 3 } & Stress Score & Coping Score \\
\hline Mean & 8.9 & 66.1 \\
\hline Standard Deviation & 3.698 & 9.361 \\
\hline Correlation & \multicolumn{2}{|c|}{100} \\
\hline Table Value & 0.399 \\
\hline P Value & 0.197 \\
\hline Significance & \multicolumn{2}{|c|}{0.000} \\
\hline
\end{tabular}

Table 4: Positive correlation between the stress and coping scores among retired employees.

incapacity, decline in the mental faculties and feeling of the generation gap, add to the problems [17-22].

Middle-aged and older adults who rely more on escapism, distancing, and other aspects of avoidance, coping and less on cognitive restructuring and problem solving, are more likely to experience distress and depression [23]. Our study results reveal that two third of the respondents were males, nearly half of them belong either to Graduate or above qualification and having higher secondary school qualification, equal proportion of them were from nuclear and joint family, financial status of respondents shows that equal proportion of them had either above or below 15,000 monthly incomes. Furthermore the maximum of respondents had greater than 30 years of experience and minority had less than 30 years of experience.

The present study indicates that maximum number of respondents had either moderate level or mild level of stress while as one third of respondents was without any stress. The present study results were supported by the findings of other Indian studies. G Mani found among 100 inmates of an old age home nearly $18 \%$ of the participants had high stress scores and majority i.e., $60 \%$ had moderate stress scores [24]. Kaur $\mathrm{M}$ also conducted a study to identify common stressors among urban and rural elderly population and findings revealed that about $93 \%$ and $70 \%$ of subjects were in the mild psychosocial stress in urban and rural areas respectively while $30 \%$ of the rural subjects were in moderate psychosocial stress [25]. Our study results are also in unison with studies done outside India. The results of study conducted in Kenya by Osano [26] revealed that most of the participants were experiencing high levels of stress. Heybroek [27] in Australia found that retirement may be associated with low levels of life satisfaction and high levels of stress. The same point is confirmed by Oniye [28] in Nigeria where the findings of the study revealed that retired civil servants were experiencing stressful retirement. Similar findings were reported by Nweke [29] in Nigeria who found that retirees face many challenges which put them under stressful conditions. This might be due to the fact that during the working years the person's life is organized around the job. So after retirement many retirees may find themselves adjusting to a new routine or no routine, moving away from friends or family, feeling socially isolated and dealing with increasing medical issues. Money stress often accompanies retirement due to living on a fixed income at a lower standard of living. Retirees are confronted with important potential stressors in retirement often relating to loss of work and changes related to aging. For many retirees, this life stage brings losses to cognitive and physical capacities, health, and loved one [30].

The same point is contradicted by Coursolle et al. [31] in USA who found that retirement may come more as a relief than a stressor for individuals previously experiencing high levels of work demands interfering with family life.

The present study indicates that there is dominance of average level of coping among retirees as expressed by majority of retirees. The present result was in conformity with the findings of a quantitative study conducted by Bagheri-Nesami M in regarding Coping Strategies of Iranian Elderly Women. Findings of study revealed that participants used problem-focused and emotion-focused strategies to manage agerelated changes and to keep themselves away from harm [32]. The study was also in conformity with the findings of study conducted by Feryad A regarding Coping strategies used by South Asian women, living in the UK, and suffering from depression. Findings of study revealed that coping strategies included religion and prayer, talking; crying and self-harm [33] on the same way, Glenn [34] in Australia found that most of the participants used pro- active and passive coping styles for retirement adjustment. In line with this result, Herzig in Canada clarified that more successful coopers appear to have a repertoire of many coping strategies and strategically select combinations of coping strategies for use in particular situations. These findings go in line with Nunes et al. [35] in Brazil who indicated that, among all the coping strategies, the most used were the Religious Practices.

There is significant co-relation between the level of stress and coping scores among retired employees. The present findings are in relation with the findings of study conducted by Singh A to investigate the relationships among depression, loneliness and sociability in elderly people. Findings of study revealed that elderly experience loneliness and depression in old age, either as a result of living alone or due to lack of close family ties and reduced connections with their culture of origin, which results in an inability to actively participate in the community activities thus providing a line of relation between stresses and coping [36]. The findings of present study were in relation to the findings of study conducted by Juliana Nery de Souza on Stress symptoms and coping strategies. Study findings revealed that Elderly subjects present stress symptoms due to physical, psychological and social changes during aging process and elderly subjects mainly elected problem-focused coping, stress intensity was independent of the coping style, showing that both problem- and emotion-focused coping are associated with similar stress levels [37].

The present study was also supported by findings of study conducted by Kraaji V which revealed that task-oriented coping and emotion-oriented coping both appeared to be directly related to depressive symptoms and emotion-oriented coping moderated the impact of stress to varying degrees, depending on the amount of stress experienced [38] 
Citation: Dar SA, Iliyas I, Dilawar T, Rahman T (2018) A Descriptive Study on Perceived Levels of Stress, Coping and Their Correlation in Retirees of Kashmir Valley. J Psychiatry 21: 443. doi:10.4172/2378-5756.1000443

\section{Conclusion}

We conclude with the message that the level of stress was moderate among retired employees and the retirees used average level of coping to deal with the retirement stress. Significant positive relation was found between the stress and coping scores among retired employees. We recommend that employees should be provided with preretirement education about coping with post-retirement stress, postretirement counseling about effective coping strategies for managing post-retirement concerns.

\section{Funding}

Nil.

\section{Conflict of interest}

None declared.

\section{References}

1. Park K (2002) Preventive and Social Medicine (23rd edn.). M/s Banarsidas Bhanot, Jabalpur, India. pp: 408-410.

2. Atchley RC (1971) The social forces in later life: An introduction to socia gerontology (2nd edn.). Belmont, California Wards worth.

3. Jeyalakshmi S, Chakrabarti S, Gupta N (2011) Situation analysis of the elderly in India.

4. Stuart GW (2006) Principles and practices of psychiatric nursing (1st edn.). JP Brothers, New Delhi. pp: 245-247.

5. http://www.medicineonline.com/articles/5/2/stress-an

6. SreeVani R (2010) A guide to mental health and psychiatric nursing (3rd edn.). JP Brothers Medical, New Delhi. pp: 108-111.

7. http://www.mospi.nic.in/

8. http://www.gerontologyindia.com/

9. http://www.squidoo.com/

10. Shebeer BP, Yaseen KS (2013) A concise text book of advanced nursing practice. Stress and adaptation. EMMESS Medical Publications. pp: 625- 631.

11. www.cdc.gov/aging/..../mental -health pdf

12. Goodman LA (1961) Snowball sampling. Ann Math Stat 32: 148-170.

13. Lovibond SH, Lovibond PF (1995) Manual for the depression anxiety stress scales. Psychology foundation monograph. School of Psychology, University of New South Wales, Sydney, Australia.

14. Carver CS (1997) You want to measure coping but your protocol's too long: Consider the Brief COPE. Int J Behav Med 4: 92-100.

15. Banker K, Prajapati B, Kedia G (2011) Study of health profile of residents of geriatric home in Ahmedabad district. Natl J Community Med 2: 378-382.

16. Moos RH, Brennan PL, Schutte KK, Moos BS (2006) Older adults' coping with negative life events: Common processes of managing health, interpersonal, and financial/work stressors. Int J Aging Hum Dev 62: 39-59.

17. Krause N, Jay G, Liang J (1991) Financial strain and psychological well-being among the American and Japanese elderly. Psychol Aging 6: 170-181.

18. Holden KC, Burkhauser RV, Myers DA (1986) Income transitions at older stages of life: The dynamics of poverty. Gerontologist 26: 292-297.
19. Fitzpatrick TR (1998) Bereavement events among elderly men: The effects of stress and health. J Appl Gerontol 17: 204-228.

20. Yang T, Rockett IR, Lv Q, Cottrell RR (2012) Stress status and related characteristics among urban residents: A six-province capital cities study in China. PLoS One 7: e30521.

21. Wang JJ (2001) Prevalence and correlates of depressive symptoms in the elderly of rural communities in southern Taiwan. J Nurs Res 9: 1-12.

22. Pruchno RA, Burant CJ, Peters ND (1997) Coping strategies of people living in multigenerational households: effects on well-being. Psychol Aging 12: 115-24

23. Mani G, Udayakumar S, Annamalai K, Ramasamy DJ (2014) Perceived levels of stress and its correlates among residents of old age home in Kanchipuram District, Tamil Nadu. Med J DY Patil Univ 7: 728-731.

24. Kaur M, Kaur A, Saggu A, Kaur A, Kaur A, et al. (2006) Comparative study on psychosocial stresses among urban and rural geriatric population in selected areas of district Ludhiana (Punjab). Nursing and Midwifery Research Journal.

25. Osano SO (2011) Impact of retirement on stress levels of retired primary schoo teachers between 1995-2004: A case of Rachuonyo district, Kenya. Egerton University, Kenya. pp: 1-62.

26. Heybroek L (2011) Life satisfaction and retirement: A latent growth mixture modeling approach. 10th Anniversary Research Conference of Household Income and Labor Dynamics in Australia (HILDA), University of Melbourne, Australia. pp: 1-42

27. Oniye AO (2012) Retirement stress and management strategies among retired civil servants in Kwara state: Counseling implication and interventions. International Journal of Educational Management 26: 43-52.

28. Nweke JO (2015) Post-retirement stress under non-contributory pension regime: A study of retired civil servants in Ebonyi State Nigeria. Canadian Social Science 11: 109-117.

29. Abd-Allah ES, Ahmed RAR, Ahmed FM (2017) Stress appraisal and perceived coping strategies among Zagazig University retired employees. IOSR Journal of Nursing and Health Science 6: 27-35.

30. Coursolle KM, Sweeney MM, Raymo JM (2010) The association between retirement and emotional well-being: Does prior work-family conflict matter? Journal of gerontology: psychological sciences and social sciences 65B: 609620

31. Masoumeh BN, Forough R, Fatemeh OSH (2010) Coping strategies of Iranian elderly women: A qualitative study. Educational Gerontology 36: 573-591.

32. Feryad AH, Ray C (2010) Living with depression: Coping strategies used by South Asian women, living in the UK, suffering from depression. Journal of Mental Health, Religion and Culture 6: 21-44

33. Glenn MG (2007) Retirement: Effects of a psycho educational program. Bond University, Queensland, Australia. pp: 1-80.

34. Herzig AJ (2014) Optimizing well-being in retirement: Summarizing three decades of research on successful coping in retirement. Mind Pad 4: 32-37.

35. Nunes RP, de Melo RLP, Júnior EG, Eulálio MD (2016) Relationship between coping and subjective well-being of elderly from the interior of the Brazilian Northeast. Psychology: Research and Review 29: 33.

36. Singh A, Misra N (2009) Loneliness, depression and sociability in old age. Ind Psychiatry J 18: 51-55.

37. de Souza-Talarico JN, Paulo C, Ricardo N, Eliane CC (2009) Stress symptoms and coping strategies in healthy elderly subjects. Rev Esc Enferm USP 43 803-809.

38. Kraaij V, Garnefski N, Maes S (2002) The joint effects of stress, coping, and coping resources on depressive symptoms in the elderly. Anxiety, Stress \& Coping: An International Journal 15: 163-177. 